\title{
Prevalence and genotyping of Toxoplasma gondii in naturally-infected synanthropic rats (Rattus norvegicus) and mice (Mus musculus) in eastern China
}

\author{
Chao Yan ${ }^{1+}$, Li-Jun Liang ${ }^{1,2+}$, Bei-Bei Zhang ${ }^{1}$, Zhi-Long Lou ${ }^{3}$, Hui-Feng Zhang ${ }^{1,2}$, Xuan Shen ${ }^{1,2}$, Yu-Qing Wu ${ }^{1,4}$, \\ Zi-Mu Wang ${ }^{1,2}$, Ren-Xian Tang ${ }^{1}$, Lin-Lin Fu ${ }^{1}$ and Kui-Yang Zheng ${ }^{{ }^{*}}$
}

\begin{abstract}
Background: Synanthropic rats and mice share the same environment with humans and play an important role in epidemiology of toxoplasmosis; however, there is limited information about prevalence and genetic characterization of Toxoplasma gondii in synanthropic rats and mice in China.

Findings: In the present study, the prevalence and genetic characterization of $T$. gondii naturally infected synanthropic rodents (Rattus norvegicus and Mus musculus) were investigated in the urban area of Xuzhou city, Eastern China between June 2013 and August 2014. DNA from the brain of each animal was prepared and screened by specific PCR assay targeting 35-fold repeated B1 gene (B1-PCR). PCR positive DNA samples were further genotyped by multi-locus PCR-RFLP. Overall, out of 123 synanthropic rodents, 29 samples were positive by B1 gene-targeted PCR (23.6\%). Of these, 7 out of 31 (22.3\%) M. musculus were positive, whereas the positive rate of $R$. norvegicus was 23.9\% (22/92). Multi-locus PCR-RFLP analysis reveals that seven PCR-positive samples were completely genotyped and they were identified as type China 1 (ToxoDB\# 9).

Conclusion: To our knowledge, this is the first report of molecular detection and genetic characterization of $T$. gondii infection in synanthropic rodents in Eastern China. The results of the present study showed a high infection pressure of $T$. gondii exists in the environment and synanthropic rodents infected by $T$. gondii may be an important source of infection for cats and other animals.
\end{abstract}

Keywords: Prevalence, Toxoplasma gondii, Genetic characterization, Synanthropic rodent, Eastern China

\section{Background}

Toxoplasmosis caused by the obligatory intracellular protozoan Toxoplasma gondii is a widespread zoonosis [1]. It is estimated that up to $30 \%$ of the human population of the world is suffering chronic infection with generally benign or mild nonspecific clinical symptoms [2] Moreover, deaths and great morbidity can be brought about in fetuses and immunocompromised patients [3]. Humans and other animals can get infected mainly

\footnotetext{
*Correspondence: ZKY02@163.com

${ }^{\dagger}$ Equal contributors

'Department of Pathogenic Biology and Immunology, Laboratory of Infection and Immunity, Xuzhou Medical College, Xuzhou, Jiangsu Province 221004, PR China

Full list of author information is available at the end of the article
}

through consumption of undercooked meats containing cysts of $T$. gondii and ingestion of oocysts in environment. In addition, $T$. gondii can be also transmitted vertically from an infected mother to her baby during her first gestation [4].

Synanthropic rodents are widely distributed in China and it has been reported that the main species of rodents distributed in China may vary due to different climates, food sources and other factors [5]. However, brown rats (Rattus norvegicus) and synanthropic mice (Mus musculus) are widely distributed in the urban area of Noth China [6]. Naturally-infected rodents serving as important reservoir hosts play a key role in dissemination of $T$. gondii to other animals including cats since 
they are the main prey for cats and other stray carnivorous animals [7]. Furthermore, free-living animals such as stray cats and rodents could be used as sentinels of environmental spreading with $T$. gondii in densely built urban areas as they are exposed without any protection to all the infective forms of the parasite and feed on various sources of food on the ground [8-10].

Our previous study showed that there was a high prevalence of $T$. gondii in stray dogs and cats both in urban and rural areas of Xuzhou city, suggesting a high infection pressure for both animals and humans in that area [11]. However, the sources for this relative high prevalence of $T$. gondii in stray dogs and cats remain unclear. Moreover, knowledge about the prevalence and genetic characterization of $T$. gondii in synanthropic rodents in China is rather limited. Therefore, in the present study, we determined the prevalence of $T$. gondii in synanthropic rodents in Eastern China by detecting T. gondii DNA using specific PCR targeting 35-fold repeated $\mathrm{B} 1$ gene (B1-PCR), and genotyped $T$. gondii in synanthropic rodents.

\section{Findings}

\section{Materials and methods}

\section{Sample collection and preparation}

A total of 123 rodents were randomly collected from Tongshan District, Yunlong District, GuLou District and Peixian County in Xuzhou City, Jiangsu Province, Eastern China during July 2013 to August 2014. The geographical information of Xuzhou City was described in detail elsewhere [11]. Animals were trapped and transported to our laboratory where the animals were anaesthetized and whole brain from each animal was obtained and stored at $-20^{\circ} \mathrm{C}$ until use. The age of animals was estimated by body's length as description elsewhere [6], and these animals were divided into four groups according to their ages: Juvenile group (with the body length $<=$ $110 \mathrm{~mm}$ ), Sub-adult group (with the body length 111$150 \mathrm{~mm}$ ), adult group (with the body length 151$175 \mathrm{~mm}$ ) and old group (with the body length $>175 \mathrm{~mm}$ ).

\section{DNA extraction and specific polymerase chain reaction}

DNA extraction was performed using a commercial DNA extraction kit (Shanghai sangon biotech, Shanghai, China) according to manufacturer's recommendations. Briefly, about $50 \mathrm{mg}$ of each brain tissue was cut into small pieces, homogenized in $200 \mu \mathrm{l}$ of DNA extraction buffer and proteinase $\mathrm{K}$, and added for ingestion at $55^{\circ} \mathrm{C}$ for $4 \mathrm{~h}$. Subsequently, $500 \mu \mathrm{l}$ buffered phenol was added and centrifuged at $12,000 \mathrm{~g}$ for $5 \mathrm{~min}$. DNA was extracted twice using phenol-chloroform, and stored at $-20^{\circ} \mathrm{C}$ until use after precipitation by sodium acetate and ethanol.

To estimate the prevalence of $T$. gondii in synanthropic rodents in Eastern China, specific PCR that targets 35-fold repeated B1 gene (B1-PCR) was employed to detect the possible infection with $T$. gondii in synanthropic rats and mice $[12,13]$. Positive control of DNA from $T$. gondii infected mice experimentally and negative controls were included in each test.

\section{Genetic characterization of $T$. gondii in positive DNA samples}

Genetic characterization of $T$. gondii in randomly selected positive DNA samples in synanthropic rodents were performed using the multilocus PCR-RFLP method [14-17]. Briefly, a total of 10 genetic markers (i.e., SAG1, SAG2, alter.SAG2, SAG3, BTUB, GRA6, c22-8, L358, PK1, and Apico) were amplified by multiplex PCR using external primers. The PCR reaction $(25 \mu \mathrm{l})$ consisting of $1 \times$ PCR buffer, $0.2 \mathrm{mM}$ of each primer, $200 \mu \mathrm{M}$ dNTPs, $2 \mathrm{mM} \mathrm{MgCl}, 0.2 \mathrm{U}$ of HotStart Taq DNA polymerase (TAKARA, Japan) were carried out using a thermal cycler (PTC 200, Bio-RAD) under the reaction conditions as follows: $95^{\circ} \mathrm{C}$ for $5 \mathrm{~min}$ to activate the DNA polymerase, then 30 cycles of PCR at $95^{\circ} \mathrm{C}$ for $30 \mathrm{~s}, 55^{\circ} \mathrm{C}$ for $60 \mathrm{~s}$ and $72^{\circ} \mathrm{C}$ for $90 \mathrm{~s}$. Six references including GT1, PTG, CTG, MAS, $\mathrm{TgCgCa} 1$ and $\mathrm{TgCatBr} 5$ were employed as positive controls in each reaction. The amplified DNA fragments were diluted 1:1 in sterile, double-distilled water and then were amplified by internal primers for each locus, respectively [14-17]. A similar approach was used for nest PCR, the annealing temperature of which is at $60^{\circ} \mathrm{C}$ for $60 \mathrm{~s}$ for all the markers except Apico $\left(55^{\circ} \mathrm{C}\right.$ for $\left.60 \mathrm{~s}\right)$. The nest PCR amplified products were then digested with

Table 1 The prevalence of Toxoplasma gondii infection in synanthropic rats and mice in Xuzhou City, Eastern China

\begin{tabular}{llll}
\hline Variable & No. examined & No. positive & Prevalence (\%) \\
\hline
\end{tabular}

Region

$\begin{array}{lrrr}\text { Tongshan District } & 26 & 6 & 23.1 \\ \text { GuLou District } & 83 & 21 & 25.3 \\ \text { Other areas } & 14 & 2 & 14.3 \\ \text { Gender } & & & \\ \quad \text { Female } & 78 & 18 & 23.1 \\ \text { Male } & 45 & 11 & 24.4 \\ \text { Age* } & & & \\ \text { Juvenile group } & 26 & 6 & 23.1 \\ \text { Sub-adults group } & 63 & 12 & 19.0 \\ \text { Adults group } & 26 & 5 & 19.2 \\ \quad \text { Old group } & 8 & 6 & 75.0 \\ \text { Species } & & & \\ \text { Mus musculus } & 31 & 7 & 22.6 \\ \text { Rattus norvegicus } & 92 & 29 & 23.9 \\ \text { Total } & 123 & \end{array}$

*Means $\mathrm{P}<0.01$ when variables were analyzed using a Chi-square test. 
Table 2 Summary of genotyping of Toxoplasma gondii in synanthropic rats and mice in China

\begin{tabular}{|c|c|c|c|c|c|c|c|c|c|c|c|c|c|c|c|}
\hline Isolate ID & Host & Tissue & Location & SAG1 & $5^{\prime}+3^{\prime}$ SAG2 & Alternative SAG2 & SAG3 & BTUB & GRA6 & c22-8 & c29-2 & L358 & PK1 & Apico & Genotype \\
\hline GT1 & Goat & & United States & 1 & I & I & 1 & 1 & I & I & 1 & I & 1 & I & Reference, Type I, ToxoDB \#10 \\
\hline PTG & Sheep & & United States & $\|/\| \|$ & $\|$ & $\|$ & $\|$ & $\|$ & $\|$ & $\|$ & $\|$ & $\|$ & $\|$ & $\|$ & Reference, Type II, ToxoDB \#1 \\
\hline CTG & Cat & & United States & $\|/\|$ & III & III & III & III & III & III & III & III & III & III & Reference, Type III, ToxoDB \#2 \\
\hline MAS & Human & & France & $u-1^{*}$ & । & $\|$ & III & III & III & $u-1^{*}$ & । & I & III & I & Reference, ToxoDB \#17 \\
\hline TgCgCa1 & Cougar & & Canada & । & $\|$ & $\|$ & III & $\|$ & $\|$ & $\|$ & $u-1^{*}$ & । & $u-2^{*}$ & I & Reference, ToxoDB \#66 \\
\hline TgCatBr5 & Cat & & Brazil & । & III & III & III & III & III & । & । & I & $u-1^{*}$ & । & Reference, ToxoDB \#19 \\
\hline TgWtdSc40 & WTD & & USA & $u-1$ & $\|$ & $\|$ & $\|$ & $\|$ & $\|$ & $\|$ & $\|$ & । & $\|$ & । & Type 12, ToxoDB \#5 \\
\hline TgCatBr64 & Cat & & Brazil & । & । & $u-1$ & III & III & III & $u-1$ & । & III & III & । & Reference, ToxoDB \#111 \\
\hline TgRsCr1 & Toucan & & Costa Rica & $u-1$ & । & $\|$ & III & । & III & $u-2$ & । & । & III & । & Reference, ToxoDB \#52 \\
\hline TgRn05 & Rat & Brain & Xuzhou, China & $u-1$ & $\|$ & $\|$ & III & III & $\|$ & $\|$ & III & $\|$ & $\|$ & 1 & ToxoDB \#9 \\
\hline Tgmouse07 & Mouse & Brain & Xuzhou, China & $u-1$ & $\|$ & $\|$ & $\|$ & III & $\|$ & $\|$ & III & $\|$ & $\|$ & I & ToxoDB \#9 \\
\hline Tgmouse08 & Mouse & Brain & Xuzhou, China & $u-1$ & $\|$ & $\|$ & III & III & $\|$ & $\|$ & III & $\|$ & $\|$ & I & ToxoDB \#9 \\
\hline TgRn13 & Rat & Brain & Xuzhou, China & $u-1$ & $\|$ & $\|$ & III & III & $\|$ & $\|$ & III & $\|$ & $\|$ & I & ToxoDB \#9 \\
\hline TgRn14 & Rat & Brain & Xuzhou, China & $u-1$ & $\|$ & $\|$ & III & III & $\|$ & $\|$ & III & $\|$ & $\|$ & I & ToxoDB \#9 \\
\hline TgRn15 & Rat & Brain & Xuzhou, China & $u-1$ & $\|$ & $\|$ & III & III & $\|$ & $\|$ & III & $\|$ & $\|$ & I & ToxoDB \#9 \\
\hline Tgmouse23 & Mouse & Brain & Xuzhou, China & $u-1$ & $\|$ & $\|$ & III & III & $\|$ & $\|$ & III & $\|$ & $\|$ & I & ToxoDB \#9 \\
\hline
\end{tabular}

${ }^{*} \mathrm{u}-1$ and $\mathrm{u}-2$ represent unique RFLP genotypes, respectively.

WTD: White-tailed Deer.

nd: not determined. 
restriction enzymes for $1 \mathrm{~h}$ at recommended temperature according to the instructions for each enzyme. The digested fragments were resolved in 2.5\%-3\% agarose gel and visualized using a gel documentation system (UVP GelDocItTM Imaging System, Cambridge, U.K.).

\section{Statistical analysis}

Differences in the prevalence of $T$. gondii-infected rats and mice among different variables including location, age and gender were analyzed using a Chi-square test by SPPS (Release 16.0 standard version, SPPS Inc., Chicago, America). Statistical differences were found when $P<0.05$.

\section{Results and discussion}

T. gondii DNA in brains was demonstrated in 29 out of $123(23.6 \%)$ rodents collected. Of these, 7 out of 31 (22.6\%) mice were $T$. gondii DNA-positive whereas the prevalence of $T$. gondii in rats was $23.9 \%$ (22 out of 92 animals examined, Table 1). There was no statisticaldifference in $T$. gondii prevalence in species, genders and regions where samples were collected. However, statistically significant difference was found in the prevalence of $T$. gondii in synanthropic rodents of different ages $(P<0.01)$, in which the prevalence of $T$. gondii in old group (75.0\%) and juvenile group $(23.1 \%)$ were significantly higher than that of sub-adult group (19.0\%) and adult group (19.2\%), respectively (Table 1), suggesting that both congenital infection and acquired infection of $T$. gondii existed in naturally infected synanthropic rodents in this area.

DNA samples were selected for genetic characterization using multilocus PCR-RFLP. Multilocus PCR-RFLP results showed that only seven DNA samples showed complete genotyping results and the genotypes were identified as ToxoDB \#9 (China 1, Table 2). Unfortunately, other DNA samples showed no results or part genotype results, thus the genotypes could not be determined.

Synanthropic rodents which share the same environment with humans are considered as an important reservoir of $T$. gondii for cats and other animals because naturally infected rodents constitute important prey for wild and synanthropic felids [18]. However, there is limited information about prevalence of $T$. gondii in synanthropic rodents in China [19]. In addition, the relative high prevalence of $T$. gondii in synanthropic rodents in the present study might partly account for the high infection rates of $T$. gondii in cats and dogs in the same area [11]. However, PCR assay can only provide a suggestive, but not conclusive evidence for $T$. gondii infection in rodents. Therefore, our results in the present study showed the preliminary but fundamental data for further studies which aim at isolating live parasites in synanthropic rodents.

The information of genetic characterization of $T$. gondii in synanthropic rodents is rather limited [20]. The genotypes identified in this study were the genotype ToxoDB \#9, which is dominantly prevalent in cats and other animals in most parts of China [21,22]. More importantly, this genotype which was also identified in naturally infected cats in this region (Eastern China) showed a moderate or high virulence to mice, indicating that the circulating $T$. gondii in cats and synanthropic rodents could cause severe toxoplasmosis in humans if it were to spread to humans [22]. Surprisingly, ToxDB \#10 and ToxDB \#205 which were also prevalent in naturallyinfected cats in this region were absent in our study, suggesting that there might be additional sources for cats infected by $T$. gondii [23].

\section{Conclusions}

This is the first report of molecular detection and genetic characterization of $T$. gondii in synanthropic rodents in Eastern China. The results of the present study revealed a wide distribution of $T$. gondii in synanthropic rats and mice in China and an identical genotype circulating in rodents in this region, which provide basic information for further prevention and control of toxoplasmosis in humans.

\section{Competing interests}

The authors declare that they have no competing interests.

\section{Authors' contributions}

KYZ, LLF and CY conceived and designed the study, CY, LJL and ZLL performed the experiments, analyzed the data, and drafted the manuscript. BBZ, ZLL, HFZ, XS, YQW and RXT helped in study design, study implementation and manuscript revision. All authors read and approved the final manuscript.

\section{Acknowledgments}

Project support was provided, in part, by National Training Programs of Innovation and Entrepreneurship for Undergraduates (20130313021), Training Programs of Innovation and Entrepreneurship for College Students in Jiangsu Province (20130313021z) and the Open Funds of the State Key Laboratory of Veterinary Etiological Biology, Lanzhou Veterinary Research Institute, Chinese Academy of Agricultural Sciences (Grant No. SKLVEB2013KFKT005).

\section{Author details}

${ }^{1}$ Department of Pathogenic Biology and Immunology, Laboratory of Infection and Immunity, Xuzhou Medical College, Xuzhou, Jiangsu Province 221004, PR China. ²Department of Clinical Medicine, Xuzhou Medical College, Xuzhou, Jiangsu Province 221004, PR China. ${ }^{3}$ State Key Laboratory of Veterinary Etiological Biology, Key Laboratory of Veterinary Parasitology of Gansu Province, Lanzhou Veterinary Research Institute, Chinese Academy of Agricultural Sciences, Lanzhou, Gansu Province 730046, PR China. ${ }^{4}$ School of Medical Technology, Xuzhou Medical College, Xuzhou, Jiangsu Province 221004, PR China.

Received: 26 November 2014 Accepted: 5 December 2014 Published: 17 December 2014

\section{References}

1. Dubey JP: Toxoplasmosis of Animals and Humans. 2nd edition. Boca Raton, Florida: CRC Press; 2010:1-313.

2. Tenter AM, Heckeroth AR, Weiss LM: Toxoplasma gondii: from animals to humans. Int J Parasitol 2000, 30:1217-1258.

3. Sibley LD, Boothroyd JC: Virulent strains of Toxoplasma gondii comprise a single clonal lineage. Nature 1992, 359:82-85.

4. Montoya JG, Liesenfeld O: Toxoplasmosis. Lancet 2004, 363:1965-1976. 
5. Zhou P, Chen Z, Li HL, Zheng H, He S, Lin RQ, Zhu XQ: Toxoplasma gondii infection in humans in China. Parasit Vectors 2011, 4:165.

6. Zheng ZM, Jiang ZK, Chen AG: Rodent Zoology. 2nd edition. Shanghai Municipality: Shanghai Jiaotong University Press; 2008:1-691 (in Chinese).

7. Dubey JP, Frenkel JK: Toxoplasmosis of rats: a review, with considerations of their value as an animal model and their possible role in epidemiology. Vet Parasitol 1998, 77:1-32.

8. Hughes JM, Williams RH, Morley EK, Cook DA, Terry RS, Murphy RG, Smith $J E$, Hide G: The prevalence of Neospora caninum and co-infection with Toxoplasma gondii by PCR analysis in naturally occurring mammal populations. Parasitology 2006, 132:29-36.

9. Meerburg BG, De Craeye S, Dierick K, Kijlstra A: Neospora caninum and Toxoplasma gondii in brain tissue of feral rodents and insectivores caught on farms in the Netherlands. Vet Parasitol 2012, 184:317-320.

10. Meireles LR, Galisteo AJ Jr, Pompeu E, Andrade HF Jr: Toxoplasma gondii spreading in an urban area evaluated by seroprevalence in free-living cats and dogs. Trop Med Int Health 2004, 9:876-881.

11. Yan C, Fu LL, Yue CL, Tang RX, Liu YS, Lv L, Shi N, Zeng P, Zhang P, Wang DH, Zhou DH, Zhu XQ, Zheng KY: Stray dogs as indicators of Toxoplasma gondii distributed in the environment the first report across an urban-rural gradient in China. Parasit Vectors 2012, 5:5.

12. Hill DE, Chirukandoth S, Dubey JP, Lunney JK, Gamble HR: Comparison of detection methods for Toxoplasma gondii in naturally and experimentally infected swine. Vet Parasitol 2006, 141:9-17.

13. Homan WL, Vercammen M, De Braekeleer J, Verschueren H: Identification of a 200- to 300-fold repetitive 529 bp DNA fragment in Toxoplasma gondii, and its use for diagnostic and quantitative PCR. Int J Parasitol 2000, 30:69-75.

14. Tian YM, Huang SY, Miao Q, Jiang HH, Yang JF, Su C, Zhu XQ, Zou FC: Genetic characterization of Toxoplasma gondii from cats in Yunnan Province, Southwestern China. Parasit Vectors 2014, 7:178.

15. Jiang HH, Huang SY, Zhou DH, Zhang XX, Su C, Deng SZ, Zhu XQ: Genetic characterization of Toxoplasma gondii from pigs from different localities in China by PCR-RFLP. Parasit Vectors 2013, 6:227.

16. Zhang XX, Lou ZZ, Huang SY, Zhou DH, Jia WZ, Su C, Zhu XQ Genetic characterization of Toxoplasma gondii from Qinghai vole, Plateau pika and Tibetan ground-tit on the Qinghai-Tibet Plateau, China. Parasit Vectors 2013, 6:291.

17. Chen J, Li ZY, Zhou DH, Liu GH, Zhu XQ: Genetic diversity among Toxoplasma gondii strains from different hosts and geographical regions revealed by sequence analysis of GRA5 gene. Parasit Vectors 2012, 5:279.

18. Murphy RG, Williams RH, Hughes JM, Hide G, Ford NJ, Oldbury DJ: The urban house mouse (Mus domesticus) as a reservoir of infection for the human parasite Toxoplasma gondii: an unrecognised public health issue? Int J Environ Health Res 2008, 18:177-185.

19. Yin CC, He Y, Zhou DH, Yan C, He XH, Wu SM, Zhou Y, Yuan ZG, Lin RQ, Zhu XQ: Seroprevalence of Toxoplasma gondii in Rats in Southern China. J Parasitol 2010, 96:1233-1234.

20. Wang L, Cheng HW, Huang KQ, Xu YH, Li YN, Du J, Yu L, Luo QL, Wei W, Jiang L, Shen JL: Toxoplasma gondii prevalence in food animals and rodents in different regions of China: isolation, genotyping and mouse pathogenicity. Parasit Vectors 2013, 6:273.

21. Dubey JP, Zhu XQ, Sundar N, Zhang H, Kwok OC, Su C: Genetic and biologic characterization of Toxoplasma gondii isolates of cats from China. Vet Parasitol 2007, 145:352-356.

22. Zhou P, Zhang $H$, Lin RQ, Zhang DL, Song $H Q$, Su C, Zhu XQ: Genetic characterization of Toxoplasma gondii isolates from China. Parasitol Int 2009, 58:193-195.

23. Wang L, Chen H, Liu D, Huo X, Gao J, Song X, Xu X, Huang K, Liu W, Wang Y, Lu F, Lun ZR, Luo Q, Wang X, Shen J: Genotypes and mouse virulence of Toxoplasma gondii isolates from animals and humans in China. PLoS One 2013, 8:e53483.

doi:10.1186/s13071-014-0591-6

Cite this article as: Yan et al:: Prevalence and genotyping of Toxoplasma gondii in naturally-infected synanthropic rats (Rattus norvegicus) and mice (Mus musculus) in eastern China. Parasites \& Vectors 2014 7:591.

\section{Submit your next manuscript to BioMed Central and take full advantage of:}

- Convenient online submission

- Thorough peer review

- No space constraints or color figure charges

- Immediate publication on acceptance

- Inclusion in PubMed, CAS, Scopus and Google Scholar

- Research which is freely available for redistribution

Submit your manuscript at www.biomedcentral.com/submit
() Biomed Central 